\title{
Major trauma in the elderly: The effects of ageing on ED assessment
}

\section{By Elaine Cole}

C anada's population is ageing. In 2016, there were more people aged 65 and over than those aged 17 and under (Statistics Canada, 2016). This population change is predicted to continue and by 2036 one quarter of people in Canada will be aged 65 or more (Canadian Medical Association, 2016). Improvements in health, social care and lifestyle have resulted in people living for longer and many are remaining relatively active, therefore the incidence of traumatic injury in this age group is rising. The proportion of elderly trauma presenting to the Emergency Department (ED) is growing annually (Kozar et al., 2015) and the volume of older people with significant injury is expected make up more than a third (39\%) of global trauma admissions by 2050 (Banks \& Lewis, 2013).

Unlike pediatric trauma care, the optimal management of elderly trauma currently lacks age-specific treatment guidelines and clinical protocols. Many severely injured older patients have altered responses to shock and injury, which present unique challenges for the ED trauma team (Bradburn et al., 2012). Increased age is associated with a progressive decline in physiological function, which alters the body's ability to respond to traumatic injury (Panda et al., 2009), especially in frail elderly patients with multiple health problems (Joseph et al., 2017). Older trauma patients are frequently under-triaged (Ichwan et al., 2015; Reske-Nielsen \& Medzon, 2016) and co-existing diseases or medications may alter signs or symptoms of injury (Llompart-Pou, PerezBarcena, Chico-Fernandez, Sanchez-Casado, \& Raurich, 2017). These factors can cause delays to accessing expert care or initial misdiagnosis, both of which contribute to poor outcomes after traumatic injury (Hranjec, Sawyer, Young, Swenson, \& Calland, 2012). Whilst integrated geriatric trauma services in Canada (Wong et al., 2017) and the U.S. (Wiles, Day, \& Harris, 2016) are known to improve outcomes, this remains an aspiration for many hospitals and the responsibility for initially managing older trauma lies with the ED team.

This paper will discuss some of the age-related differences that may influence the assessment and management of elderly trauma patients in the ED. For the purposes of this paper 'elderly', 'geriatric' or 'older' describe patients aged 65 years or over, whilst acknowledging that this may differ between clinical settings.

\section{Mechanisms of injury in elderly trauma}

In comparison to younger adults, older people can sustain a significant injury from a relatively trivial or minor mechanism (Cryer, 2013). Blunt trauma dominates in this age group (Adams et al., 2012; Dinh, Roncal, Byrne, \& Petchell, 2013), and a quarter of severe trauma will result from road traffic collisions (Bonne \& Schuerer, 2013). However, it has become increasingly apparent that the most common mechanism of injury in older people is falling (Gillespie et al., 2012; Kozar et al., 2015; TARN, 2017).
The more active 'younger elderly' may fall outdoors (Kelsey, Procter-Gray, Hannan, \& Li, 2012; Kim, 2016), but many older people fall indoors in so-called low-level or low-energy falls (Gelbard et al., 2014; TARN, 2017). Whilst low-level falls are usually uncomplicated for younger patients, they are the leading cause of traumatic brain injury (TBI) and mortality for older trauma (Carpenter et al., 2014; Llompart-Pou et al., 2017). Despite this, many trauma triage or ED trauma protocols currently do not have low-level falls as an activation criterion. Warfarin (Coumadin) use is common in the elderly and the need for emergency reversal to minimize brain (and other) hemorrhage is well documented. However, many patients in Canada are now prescribed Direct Oral Anticoagulants (DOACs) (Wood et al., 2017) and unlike Warfarin, not all DOACs - such as Rivaroxaban - have reversal agents (Barletta et al., 2017; Kobayashi et al., 2017). The risks of adverse outcomes and mortality after a fall are increased in anticoagulated elderly trauma patients (Boltz, Podany, Hollenbeak, \& Armen, 2015). For the ED nurse, falls in older patients warrant a high index of suspicion for severe injury, especially in the presence of oral anticoagulants. The underlying cause of the fall also requires investigation.

\section{Initial assessment of elderly trauma and the effects of ageing}

The physiology of the ageing process means that the 'normal' physiological response to injury may differ in older patients. Comorbid diseases may further complicate this and approximately $75 \%$ of older people in Canada report having one or more chronic conditions (Canadian Institute for Health Information, 2014). Comorbid (or co-existing) diseases and the associated medications challenge 'normal' trauma assessment where beta-blockers or pacemakers may mask abnormal vital signs such as tachycardia (Bonne \& Schuerer, 2013; Stevens \& Torke, 2016).

\section{Airway assessment and cervical spine immobilization}

Timely airway assessment and management is a priority as for any trauma patient. However, there is an increased risk of an obstructed airway in the elderly due to foreign bodies such as dental prosthetics or lose decaying teeth (Dalton, Rushing, Escott \& Monroe 2015). Further, the requirement for in-line cervical spine immobilization may be challenged by factors such as kyphosis, lordosis or degenerative disorders of the neck and no attempts to force the patient into a supine position should be made (Rao, Phan, Mobbs, Wilson \& Ball 2016). Finally, there is an increased incidence of occult (or undetected) cervical spine injuries in elderly head injured patients (Kozar et al., 2015). Therefore, if TBI is suspected, the cervical spine should be included in the head CT scan. 


\section{Respiratory assessment}

Ageing is associated with decreased respiratory reserve, as lung tissue becomes increasingly inelastic and alveolar function diminishes (Johnson, Botros, Groban, \& Bryan, 2015). Chronic lung diseases such as emphysema or COPD increase the risk of respiratory failure in the elderly. Furthermore, the thoracic rib cage is stiffer and even 'minor' chest injury or single rib fractures could lead to significant respiratory complications (Wardhan, 2013). Age-related physiological changes to the respiratory system and co-morbid disease can result in oxygen saturation levels being low ( $<95 \%$ on air) in the pre-injury state. However lower Sp02 saturations in elderly trauma should be considered abnormal until injury is ruled out. Radiation exposure is not a concern in this age group and early chest x-ray (or CT scan) is essential to detect thoracic injuries.

\section{Cardiovascular assessment}

Elderly trauma is anecdotally considered to be 'head injuries and hip fractures'. Yet, a recent British study reported that major hemorrhage is a significant burden in older trauma patients (Stanworth et al., 2016). During cardiovascular trauma assessment in the ED, abnormal vital signs (such as tachycardia and hypotension) are usually indicators for trauma team activation (Heffernan et al., 2010). However initial systolic BP (SBP) and heart rate are poor at predicting serious injury amongst older adults (Newgard et al., 2014). Greater than 50\% of the geriatric population suffer underlying hypertension and cardiovascular disease (Bonne \& Schuerer, 2013) where a 'normal' SBP may be $150 \mathrm{mmHg}$ or higher. It is, therefore, difficult to assess hypotension in these patients and traditionally accepted vital signs such $\mathrm{SBP}<90 \mathrm{mmHg}$ may be extremely low or pre-terminal for some older people (Heffernan et al., 2010). Adults between the ages of 65 and 95 years will vary greatly as age increases, therefore there can be no 'one size fits all' for a hypotensive threshold for older people.

However, recent reports suggest that higher values of SBP $<110$ to $117 \mathrm{~mm} \mathrm{Hg}$ are more sensitive in predicting hypotension, severe injury and mortality in older trauma (Brown et al., 2015; Newgard et al., 2014; Oyetunji et al., 2011). To assist with assessment of hemorrhage in the elderly laboratory markers of hypoperfusion such as lactate or base deficit may be helpful. An elevated venous lactate $\geq 2.5 \mathrm{mmol} / \mathrm{L}$ was better at identifying hemodynamic instability than SBP in older trauma (Salottolo, Mains, Offner, Bourg, \& Bar-Or, 2013) and raised lactate ( $\geq$ $2.0 \mathrm{mmol} / \mathrm{L}$ ) in elderly trauma is reported to be a risk factor for poor outcome (Vanzant et al., 2015). The American College of Surgeons suggests that a base deficit should be expedited in geriatric trauma assessment (Cryer, 2013). Base deficit values of $\geq 6 \mathrm{mEq} / \mathrm{L}$ (Base Excess $\leq-6 \mathrm{mEq} / \mathrm{L}$ ) are markers of severe injury and 60\% mortality in older trauma patients (Calland et al., 2012; Davis \& Kaups, 1998).

\section{Neurologic assessment}

Accurate neurologic assessment in elderly trauma may be challenging with pre-existing cognitive impairment such as dementia or Alzheimer's, or age-related factors such as hearing loss. The Glasgow Coma Scale (GCS) is used to determine the extent of neurologic injury in patients with TBI and to identify those who may require neurosurgical care. Yet, this assessment may have limited utility in older people (Salottolo, Levy, Slone, Mains, \& Bar-Or, 2014). Studies suggest that GCS in older trauma patients may not reflect the severity of TBI and scores were found to be higher in the elderly compared to younger patients with the same severity of injury (Kehoe, Rennie, \& Smith, 2015; Kehoe et al., 2016). This is possibly due to brain atrophy, which allows more space within the cranium for a hematoma to grow, or that subdural hematomas-common in the elderly-evolve more slowly reducing GCS at a later stage (Kehoe et al., 2016; Salottolo et al., 2014). Timely CT head scanning is essential to identify and classify TBI (Carney, 2016). However, older age is associated with delay to CT scan (Kirkman et al., 2013; TARN, 2017), which may be caused, in part, by failing to recognize a reduced GCS. Once again, variations in age make it difficult to give a precise cut-off value that may indicate TBI, but GCS of 14 or less has been found to be predictive of severe injury (Newgard et al., 2014) in the elderly until proven otherwise.

In summary, identification of severe injury in elderly trauma is challenging. Age-related physiological changes and co-morbid diseases complicate the trauma assessment of older people. As the elderly population increases, it is essential that ED nurses can assess this age group appropriately.

Key messages for elderly trauma assessment in the ED include:

- Irrespective of how 'young' the external appearance of the older trauma patient is, there will be underlying changes to physiology that may mask the 'normal' signs of injury.

- Low-level falls can cause severe injury in the elderly and thorough examination is mandatory.

- Oral anticoagulants can complicate injury and worsen outcome. Early diagnostics and advice on reversal are essential.

- Vital signs may not fit 'normal' parameters:

- Low oxygen saturations should be considered trauma-related hypoxia until proven otherwise. Check the Arterial Blood Gases!

- An SBP of $<120 \mathrm{mmHg}$ may be hypotension in older people

- Lactate $\geq 2.0 \mathrm{mmol} / \mathrm{L}$ or Base Deficit $\geq 6 \mathrm{mEq} / \mathrm{L}$ may be better markers of severe injury than SBP

- 'Normal' GCS (14-15) in elderly head injury does not rule out TBI.

\section{About the author}

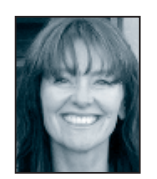

Dr. Elaine Cole: PhD, MSc, Post Grad Dip

(Education), BSc, RN. My background is in ED and critical care nursing. After a number of years working as an Advanced Practitioner in the ED, I completed my PhD in November 2014 (which examined the relationship between hemorrhage and infection after severe injury). My current role is the Director of Research and Innovation for the pan London Major Trauma System (www.londontraumasystem. org), where I support clinical innovation and collaborative research across the Greater London region. I am also one of the tutors and module leaders for the MSc Trauma Sciences at Queen Mary University of London, London, UK. 
Adams, S.D., Cotton, B.A., McGuire, M.F., Dipasupil, E., Podbielski, J.M., Zaharia, A., ... Holcomb, J.B. (2012). Unique pattern of complications in elderly trauma patients at a Level I trauma center. J Trauma Acute Care Surg, 72(1), 112-118. doi:10.1097/ TA.0b013e 318241f073

Banks, S.E., \& Lewis, M.C. (2013). Trauma in the elderly: Considerations for anesthetic management. Anesthesiol Clin, 31(1), 127-139. doi:10.1016/j.anclin.2012.11.004

Barletta, J.F., Hall, S., Sucher, J.F., Dzandu, J.K., Haley, M., \& Mangram, A.J. (2017). The impact of pre-injury direct oral anticoagulants compared to warfarin in geriatric G-60 trauma patients. European Journal of Trauma and Emergency Surgery, 43(4), 445-449. doi:10.1007/s00068-017-0772-z

Boltz, M.M., Podany, A.B., Hollenbeak, C.S., \& Armen, S.B. (2015). Injuries and outcomes associated with traumatic falls in the elderly population on oral anticoagulant therapy. Injury, 46(9), 1765-1771. doi:10.1016/j.injury.2015.06.013

Bonne, S., \& Schuerer, D.J. (2013). Trauma in the older adult: epidemiology and evolving geriatric trauma principles. Clin Geriatr Med, 29(1), 137-150. doi:10.1016/j.cger.2012.10.008

Bradburn, E., Rogers, F.B., Krasne, M., Rogers, A., Horst, M.A., Beelen, M.J., \& Miller, J.A. (2012). High-risk geriatric protocol: Improving mortality in the elderly. J Trauma Acute Care Surg, 73(2), 435-440. doi:10.1097/TA.0b013e31825c7cf4

Brown, J.B., Gestring, M.L., Forsythe, R.M., Stassen, N.A., Billiar, T.R., Peitzman, A.B., \& Sperry, J.L. (2015). Systolic blood pressure criteria in the National Trauma Triage Protocol for geriatric trauma: 110 is the new 90. J Trauma Acute Care Surg, 78(2), 352359. doi: $10.1097 /$ ta. 0000000000000523

Calland, J.F., Ingraham, A.M., Martin, N., Marshall, G.T., Schulman, C.I., Stapleton, T., \& Barraco, R.D. (2012). Evaluation and management of geriatric trauma: An Eastern Association for the Surgery of Trauma practice management guideline. J Trauma Acute Care Surg, 73(5, Suppl. 4), S345-350. doi:10.1097/ TA.0b013e318270191f

Canadian Institutefor Health Information. (2014). Health carein Canada, 2011. A focus on seniors and aging. Ottawa: Author. https://secure. cihi.ca/free_products/HCIC_2011_seniors_report_en.pdf

Canadian Medical Association. (2016). The state of seniors' healthcare in Canada. https://www.cma.ca/En/Lists/Medias/the-state-ofseniors-health-care-in-canada-september-2016.pdf

Carney, N., Totten, A., O'Reilly, C., et al. (2016). Brain Trauma Foundation. Guidelines for the management of severe traumatic brain injury (4th edition). https://braintrauma.org/ uploads/03/12/Guidelines_for_Management_of_Severe_ TBI_4th_Edition.pdf

Carpenter, C.吕., Avidan, M.S., Wildes, T., Stark, S., Fowler, S.A., \& Lo, A.X. (2014). Predicting geriatric falls following an episode of emergency department care: A systematic review. Acad Emerg Med, 21(10), 1069-1082. doi:10.1111/acem.12488

Cryer, H.G., Calland, J.F., Chow, W., Davis, M., Hemmila, M., Kosar, R., Lopez, S., ... Wong, C. (2013). American College of Surgeons Trauma Quality Improvement Geriatric Trauma Management Guidelines. https://www.facs.org/ /media/files/quality\%20 programs/trauma/tqip/geriatric\%20guide\%20tqip.ashx

Dalton, T., Rushing, M.R, Escott, M.E., \& Monroe, B.J. (2015) Complexities of geriatric trauma patients. JEMS. http://www.jems. $\mathrm{com} /$ articles/print/volume-40/issue-11/features/complexitiesof-geriatric-trauma-patients.html

Davis, J.W., \& Kaups, K.L. (1998). Base deficit in the elderly: A marker of severe injury and death. J Trauma, 45(5), 873-877.

Dinh, M.M., Roncal, S., Byrne, C.M., \& Petchell, J. (2013). Growing trend in older patients with severe injuries: Mortality and mechanisms of injury between 1991 and 2010 at an inner city major trauma centre. ANZ J Surg, 83(1-2), 65-69. doi:10.1111/j.1445-2197.2012.06180.x

Gelbard, R., Inaba, K., Okoye, O.T., Morrell, M., Saadi, Z., Lam, L., ... Demetriades, D. (2014). Falls in the elderly: A modern look at an old problem. Am J Surg, 208(2), 249-253. doi:10.1016/j. amjsurg.2013.12.034

Gillespie, L.D., Robertson, M.C., Gillespie, W.J., Sherrington, C., Gates, S., Clemson, L.M., \& Lamb, S.E. (2012). Interventions for preventing falls in older people living in the community. Cochrane Database Syst Rev(9), Cd007146. doi:10.1002/14651858. CD007146.pub3

Heffernan, D.S., Thakkar, R.K., Monaghan, S.F., Ravindran, R., Adams, C.A., Jr., Kozloff, M.S., ... Cioff, W.G. (2010). Normal presenting vital signs are unreliable in geriatric blunt trauma victims. $J$ Trauma, 69(4), 813-820. doi:10.1097/TA.0b013e3181f41af8

Hranjec, T., Sawyer, R.G., Young, J.S., Swenson, B.R., \& Calland, J.F. (2012). Mortality factors in geriatric blunt trauma patients: Creation of a highly predictive statistical model for mortality using 50,765 consecutive elderly trauma admissions from the National Sample Project. Am Surg, 78(12), 1369-1375.

Ichwan, B., Darbha, S., Shah, M.N., Thompson, L., Evans, D.C., Boulger, C.T., \& Caterino, J.M. (2015). Geriatric-specific triage criteria are more sensitive than standard adult criteria in identifying need for trauma center care in injured older adults. Ann Emerg Med, 65(1), 92-100.e103. doi:10.1016/j.annemergmed.2014.04.019

Johnson, K.N., Botros, D.B., Groban, L., \& Bryan, Y.F. (2015). Anatomic and physiopathologic changes affecting the airway of the elderly patient: Implications for geriatric-focused airway management. Clin Interv Aging, 10, 1925-1934. doi:10.2147/cia.s93796

Joseph, B., Orouji Jokar, T., Hassan, A., Azim, A., Mohler, M.J., Kulvatunyou, N., ... Rhee, P. (2017). Redefining the association between old age and poor outcomes after trauma: The impact of frailty syndrome. J Trauma Acute Care Surg, 82(3), 575-581. doi: $10.1097 /$ ta.0000000000001329

Kehoe, A., Rennie, S., \& Smith, J.E. (2015). Glasgow Coma Scale is unreliable for the prediction of severe head injury in elderly trauma patients. Emerg Med J, 32(8), 613-615. doi:10.1136/ emermed-2013-203488

Kehoe, A., Smith, J.E., Bouamra, O., Edwards, A., Yates, D., \& Lecky, F. (2016). Older patients with traumatic brain injury present with a higher GCS score than younger patients for a given severity of injury. Emerg Med J, 33(6), 381-385. doi:10.1136/ emermed-2015-205180

Kelsey, J.L., Procter-Gray, E., Hannan, M.T., \& Li, W. (2012). Heterogeneity of falls among older adults: Implications for public health prevention. Am J Public Health, 102(11), 2149-2156. doi:10.2105/ajph.2012.300677

Kim, S.H. (2016). Risk factors for severe injury following indoor and outdoor falls in geriatric patients. Arch Gerontol Geriatr, 62, 75-82. doi:10.1016/j.archger.2015.10.003

Kirkman, M.A., Jenks, T., Bouamra, O., Edwards, A., Yates, D., \& Wilson, M.H. (2013). Increased mortality associated with cerebral contusions following trauma in the elderly: Bad patients or bad management? J Neurotrauma, 30(16), 1385-1390. doi:10.1089/ neu.2013.2881

Kobayashi, L., Barmparas, G., Bosarge, P., Brown, C.V., Bukur, M., Carrick, M.M., ... Coimbra, R. (2017). Novel oral anticoagulants and trauma: The results of a prospective American Association for the Surgery of Trauma Multi-Institutional Trial. J Trauma Acute Care Surg, 82(5), 827-835. doi:10.1097/ta.0000000000001414

Kozar, R.A., Arbabi, S., Stein, D.M., Shackford, S.R., Barraco, R.D., Biffl, W.L., ... Luchette, F. (2015). Injury in the aged: Geriatric trauma care at the crossroads. J Trauma Acute Care Surg, 78(6), 1197-1209. doi:10.1097/ta.0000000000000656 
Llompart-Pou, J.A., Perez-Barcena, J., Chico-Fernandez, M., SanchezCasado, M., \& Raurich, J.M. (2017). Severe trauma in the geriatric population. World J Crit Care Med, 6(2), 99-106. doi:10.5492/ wjccm.v6.i2.99

Newgard, C.D., Richardson, D., Holmes, J.F., Rea, T.D., Hsia, R.Y., Mann, N.C., ... Haukoos, J.S. (2014). Physiologic field triage criteria for identifying seriously injured older adults. Prehosp Emerg Care, 18(4), 461-470. doi:10.3109/10903127.2014.9127 07

Oyetunji, T.A., Chang, D.C., Crompton, J.G., Greene, W.R., Efron, D.T., Haut, E.R., ... Haider, A.H. (2011). Redefining hypotension in the elderly: Normotension is not reassuring. Arch Surg, 146(7), 865-869. doi:10.1001/archsurg.2011.154

Panda, A., Arjona, A., Sapey, E., Bai, F., Fikrig, E., Montgomery, R.R., ... Shaw, A.C. (2009). Human innate immunosenescence: Causes and consequences for immunity in old age. Trends Immunol, 30(7), 325-333. doi:10.1016/j.it.2009.05.004

Rao, P.J., Phan, K., Mobbs, R.J, Wilson, D., \& Ball, B. (2016). Cervical spine immobilization in the elderly population. J Spine Surg., 2(1), 41-46.

Reske-Nielsen, C., \& Medzon, R. (2016). Geriatric Trauma. Emerg Med Clin North Am, 34(3), 483-500. doi:10.1016/j.emc.2016.04.004

Salottolo, K., Levy, A.S., Slone, D.S., Mains, C.W., \& Bar-Or, D. (2014). The effect of age on Glasgow Coma Scale score in patients with traumatic brain injury. JAMA Surg, 149(7), 727-734. doi:10.1001/jamasurg.2014.13

Salottolo, K.M., Mains, C.W., Offner, P.J., Bourg, P.W., \& Bar-Or, D. (2013). A retrospective analysis of geriatric trauma patients: Venous lactate is a better predictor of mortality than traditional vital signs. Scand J Trauma Resusc Emerg Med, 21, 7. doi:10.1186/1757-7241-21-7

\section{Bouquets}

Thank you to Cynthia Brown for her service as provincial representatives, representing Newfoundland and to Tayne Batiuk for representing Saskatchewan.

\section{ece.}

Thank you to Margaret Dymond for developing the Canadian Emergency Nursing Certification Exam Prep Course, which is hosted online at www.openlearning.com. It is a free, selfpaced asynchronous course and as of October 2017, 719 students have registered to access the course materials.

\section{ece.}

Congratulations to the EPICC development team: Landon James, Monique McLaughlin, Melanie Marceau, Brian Lee and Denis Bouchard. EPICC is a hit, well done on the successful launch of EPICC Trauma!
Stanworth, S.J., Davenport, R., Curry, N., Seeney, F., Eaglestone, S., Edwards, A., ... Brohi, K. (2016). Mortality from trauma haemorrhage and opportunities for improvement in transfusion practice. Br J Surg. doi:10.1002/bjs.10052

Statistics Canada. (2016). Annual demographic estimates: Canada, Provinces and Territories (91-215-X). http:// www5.statcan.gc.ca/olc-cel/olc.action?ObjId=91-215-X $\&$ ObjType $=2 \&$ lang $=$ en $\&$ limit $=0$

Stevens, C.L., \& Torke, A.M. (2016). Geriatric trauma: A clinical and ethical review. J Trauma Nurs, 23(1), 36-41. doi:10.1097/ jtn.0000000000000179

Trauma Audit and Research Network [TARN]. (2017). Major trauma in older people. https://www.tarn.ac.uk/content/downloads/3793/ Major\%20Trauma\%20in\%20Older\%20People\%202017.pdf

Vanzant, E.L., Hilton, R.E., Lopez, C.M., Zhang, J., Ungaro, R.F., Gentile, L.F., ... Efron, P.A. (2015). Advanced age is associated with worsened outcomes and a unique genomic response in severely injured patients with hemorrhagic shock. Crit Care, 19, 77. doi:10.1186/s13054-015-0788-x

Wardhan, R. (2013). Assessment and management of rib fracture pain in geriatric population: An ode to old age. Curr Opin Anaesthesiol, 26(5), 626-631. doi:10.1097/01.aco.0000432516.93715.a7

Wiles, L.L., Day, M.D., \& Harris, L. (2016). Delta alerts: Changing outcomes in geriatric trauma. J Trauma Nurs, 23(4), 189-193. doi: $10.1097 /$ jtn.0000000000000215

Wong, C.L., Al Atia, R., McFarlan, A., Lee, H.Y., Valiaveettil, C., \& Haas, B. (2017). Sustainability of a proactive geriatric trauma consultation service. Can J Surg, 60(1), 14-18.

Wood, B., Nascimento, B., Rizoli, S., Sholzberg, M., McFarlan, A., Phillips, A., \& Ackery, A.D. (2017). The anticoagulated trauma patient in the age of the direct oral anticoagulants: A Canadian perspective. Scand J Trauma Resusc Emerg Med, 25(1), 76. doi:10.1186/s13049-017-0420-y

Congratulations to Cathy Sendecki and Donna Gallant who were awarded Honorary Lifetime Membership Awards in recognition of their lengthy and faithful service to emergency nurses.

ec.

The following emergency nurses were awarded NENA bursaries at the NENA AGM in Charlottetown in May: Christina Graham and Kyla Neary Griffiths (Margaret Smith Award); Loree Vint (Debbie Cotton Award); Monique McLaughlin; Leah Chesney; Janet Calnan; Sharron Lyons; Tanya Penney; and Christina Follador. Congratulations to each of you! 